\section{Anti-inflammatory activity of Syzygium cumini leaf against experimentally induced acute and chronic inflammations in rodents}

\author{
Anirban Roy, 1 Sanjib Bhattacharya,2 \\ Jitendra N. Pandey, 1 \\ Moulisha Biswas1 \\ 1Bengal Institute of Pharmaceutical \\ Sciences, West Bengal; 2Bengal School \\ of Technology (A College of Pharmacy), \\ West Bengal, India
}

\section{Abstract}

Syzygium cumini (L.) Skeels (Myrtaceae), commonly known as Jam in Bengali, Jamun in Hindi and Black Plum or Black Berry in English, is a large size evergreen tree indigenous to India and is cultivated for its fruits. In the present study, the methanol extract of leaves from $S$. cumini (MESC) was evaluated for anti-inflammatory activity in experimental acute (carrageenan, histamine and serotonin induced rat paw oedema) and chronic models (cotton pellet induced rat granuloma). In all the models, the MESC (100 and $200 \mathrm{mg} / \mathrm{kg}$ body wt. p.o.) exhibited significant antiinflammatory activity $(\mathrm{P}<0.001)$ in a dose dependent manner. These findings revealed that the $S$. cumini leaf had remarkable acute and chronic anti-inflammatory actions in the tested rodent models.

\section{Introduction}

Traditional medicine worldwide is being reevaluated by extensive research on different plant species and their therapeutic principles. The rich wealth of plant kingdom can represent a novel source of new compounds with therapeutic activity. The major merits of herbal medicine seem to be their perceived efficacy, low incidence of serious adverse effects and low cost.

Syzygium cumini (L.) Skeels (Synonym: Eugenia jambolana Lam.), a member of the family Myrtaceae commonly known as Jam in Bengali, Jamun in Hindi and Black Plum or Black Berry in English, is a large size evergreen tree indigenous to India and is cultivated commercially for its consumable fruits. Besides India, it is also found in South-East Asian and Eastern African countries.1,2 Traditionally the plant has been used in India for several important medicinal purposes. The stem bark of the plant has been used as astringent, refrigerant, carminative, diuretic, digestive, antihelminthic, febrifuge, constipating, stomachic and antibacterial. The fruits and seeds are used in treatment of diabetes, pharyngitis, spleenopathy, urethrorrhea and ringworm infection. The leaves are antibacterial and used to strengthen the teeth and gums. The leaves have also been extensively used to treat diabetes, constipation, leucorrhoea, stomachalgia, fever, gastropathy, strangury, dermopathy and to inhibit blood discharge in the faeces. ${ }^{1-5}$

Several phytochemical and pharmacological investigations have been reported on this plant mainly on its stem bark, fruits and seeds. However, reports on the experimental biological studies on its leaf are scanty. The present work therefore, attempted to report the preliminary results of studies on anti-inflammatory effects of $S$. cumini leaf in experimentally induced inflammations in rodents to justify the traditional and folkloric beliefs.

\section{Materials and Methods}

\section{Plant material}

The mature leaves of Syzygium cumini (L.) Skeels (Myrtaceae), were collected during November 2010 from Nadia, West Bengal, India. The plant material was taxonomically identified at the Central National Herbarium, Botanical Survey of India, Howrah, West Bengal, India. The voucher specimen [CNH/I$\mathrm{I} /(82) / 2010 /$ Tech.II/351 ] was maintained in our research laboratory for future reference. The plant material was shade-dried with occasional shifting and then powdered with mechanical grinder, passing through sieve no. 40, and stored in an air-tight container.

\section{Extraction}

The powdered plant material (400 g) was first defatted with petroleum ether and then macerated at room temperature $\left(24-26^{\circ} \mathrm{C}\right)$ with methanol $(850 \mathrm{~mL})$ for 4 days with occasional shaking, followed by re-maceration with the same solvent for 3 more days. The macerates were combined, filtered and distilled off in reduced pressure. The resulting concentrate was vacuum dried at $40^{\circ} \mathrm{C}$ to yield the dry extract (MESC, yield: $10.45 \%$ w/w). The dry extract was kept in a vacuum desiccator until use. Preliminary phytochemical studies on MESC revealed the presence of alkaloids, triterpenoids, steroids and tannins. ${ }^{6}$

\section{Drugs and chemicals}

$\lambda$-Carrageenan (type IV) was obtained from S. D. Fine Chemicals Ltd., Bombay; 5-hydroxytryptamine hydrochloride (serotonin), hista-
Correspondence: Sanjib Bhattacharya, Pharmacognosy Division, Bengal School of Technology (A College of Pharmacy), Delhi Road, Sugandha, Hooghly 712102, West Bengal, India. E-mail: sakkwai@yahoo.com

Key words: Anti-inflammatory, chronic, mediators, Syzygium cumini, leaf.

Acknowledgements: the authors are thankful to Mr. Subir K. Pal, President \& CEO of Bengal Institute of Pharmaceutical Sciences for his kind co-operation and financial support for successful completion this work.

Received for publication: 25 May 2011.

Revision received: 3 July 2011

Accepted for publication: 4 July 2011.

This work is licensed under a Creative Commons Attribution NonCommercial 3.0 License (CC BYNC 3.0).

(C) Copyright A. Roy et al., 2011

Licensee PAGEPress, Italy

Alternative Medicine Studies 2011; 1:e6

doi:10.4081/ams.2011.e6

mine sulphate, were from Sigma Chemical Co. USA; indomethacin was from Recon, Bangalore, India.

\section{Experimental animals}

Studies were carried out using adult male Wistar albino rats of weighing 150-180 g. The animals were grouped in polyacrylic cages (38 $\mathrm{cm} \times 23 \mathrm{~cm} \times 10 \mathrm{~cm}$ ) with not more than four animals per cage and maintained under standard laboratory conditions (temperature $25 \pm 2{ }^{\circ} \mathrm{C}$, dark and light cycle $14 / 10 \mathrm{~h}$ ). They were allowed free access to standard dry pellet diet (Hindustan Lever, Kolkata, India) and water ad libitum. The rats were acclimatized to laboratory condition for 10 days before commencement of experiment. All experimental methods were reviewed and approved by the Institutional Animal Ethical Committee.

\section{Acute toxicity}

The oral $\mathrm{LD}_{50}$ value of MESC in male Swiss albino mice were determined as per reported method.?

\section{Evaluation of anti-inflammatory activity}

\section{Carrageenan-induced rat paw oedema}

The rats were divided into four groups $(n=6)$. The first group (which served as control) received normal saline $(0.9 \% \mathrm{w} / \mathrm{v}, 3$ $\mathrm{mL} / \mathrm{kg}$ body wt., p.o.). The second and third group received the test extract MESC (100 and $200 \mathrm{mg} / \mathrm{kg}$ body wt., p.o., respectively). The fourth group (which served as reference) 
received indomethacin $(10 \mathrm{mg} / \mathrm{kg}$ body wt., p.o.). After 30 mins, acute inflammation was produced by the sub-plantar administration of $0.1 \mathrm{~mL}$ of $1 \%(\mathrm{w} / \mathrm{v})$ of freshly prepared suspension of carrageenan in the right hind paw of each rat. The paw volume was measured at $0 \mathrm{~h}$ and $4 \mathrm{~h}$ after carrageenan injection by using plethysmometer (Ugo Basile, Italy). The difference between the two readings was taken as the volume of oedema and the percentage of inhibition was calculated by using the following formula. ${ }^{8-9}$ (Control - Treated/Control) $\times$ $100 \%$.

\section{Mediator-induced inflammation}

The paw oedema was induced in rats by subplantar injectionof $0.1 \mathrm{~mL}$ of freshly prepared histamine $(1 \mathrm{mg} / \mathrm{mL})$ and serotonin $(1 \mathrm{mg} / \mathrm{mL})$ solutions respectively. ${ }^{10,11}$ Group division and treatment regime of the animals were same as the carrageenan induced rat paw oedema model and the paw oedema was measured and calculated as described above.

\section{Cotton pellet-induced granuloma}

The animals were divided into four groups $(n=6)$. The rats were anaesthetized and sterile cotton pellets weighing $10 \pm 1 \mathrm{mg}$ were implanted subcutaneously into both sides of the groin region of each rat. The first group (which served as control) received normal saline $(0.9 \% \mathrm{w} / \mathrm{v}, 3 \mathrm{~mL} / \mathrm{kg}$ body wt., p.o.). The second and third group received the test extract MESC (100 and $200 \mathrm{mg} / \mathrm{kg}$ body wt., p.o., respectively). The fourth group (which served as reference) received indomethacin $(10 \mathrm{mg} / \mathrm{kg}$ body wt., p.o.). All groups were treated in this way for seven consecutive days from the day of cotton pellet implantation. ${ }^{12}$ On $8^{\text {th }}$ day the animals were anaesthetized and the pellets together with the granuloma tissues were carefully removed and made free from extraneous tissues. The wet pellets were then dried in an oven at $60^{\circ} \mathrm{C}$ for $24 \mathrm{~h}$ to constant weight. Increment in the dry weight of the pellets was taken as a measure of granuloma formation. ${ }^{13}$ Percentage inhibition was calculated as per the formula stated above.

\section{Statistical analysis}

The values were expressed as mean \pm standard error of mean (SEM). Statistical significance was analyzed by one-way analysis of variance (ANOVA) followed by Dunnett's post hoc test of significance. Values of $\mathrm{P}<0.001$ were considered as statistically significant.

\section{Results}

The MESC was found to be safe up to the dose of $3500 \mathrm{mg} / \mathrm{kg}$ body wt. in Swiss mice when administered orally.
Anti-inflammatory activity of $S$. cumini leaf extract (MESC) was evaluated against carrageenan induced acute paw oedema in rats and the results are summarized in Table 1 . The MESC produced significant $(\mathrm{P}<0.001)$ antiinflammatory activity in a dose dependent manner. The MESC showed maximum inhibition of $56.37 \%$ at the dose of $200 \mathrm{mg} / \mathrm{kg}$ body wt. after $4 \mathrm{~h}$ of treatment, whereas the reference drug indomethacin produced $72.06 \%$ of inhibition.

In case of histamine and serotonin induced rat paw oedema, MESC exhibited significant $(\mathrm{P}<0.001)$ and dose dependent protection from oedema (Tables 2 and 3). The MESC produced $51.01 \%$ inhibition in case of histamine and $58.75 \%$ of inhibition in case of serotonin at the dose of $200 \mathrm{mg} / \mathrm{kg}$ body wt.; while the reference drug, indomethacin produced 63.00 and 71.08 $\%$ of inhibition of rat paw oedema respectively in cases of above two mediators.

In the chronic inflammatory model (cotton pellet induced granuloma), the MESC significantly $(\mathrm{P}<0.001)$ and dose dependently reduced the weight of cotton pellets as compared to the vehicle control (Table 4). The MESC produced the maximum inhibition of $55.40 \%$ at the dose of $200 \mathrm{mg} / \mathrm{kg}$ body wt. and the reference drug indomethacin produced $63.11 \%$ of inhibition of granuloma formation in rats.

\section{Discussion}

The present study establishes the significant anti-inflammatory activity of the methanol extract from the leaf of $S$. cumini (MESC) in both experimentally induced acute and chronic inflammations in rodents. Carrageenan-induced oedema has been commonly used as an experimental animal model for acute inflammation and it is believed to be

Table 1. Effect of MESC on carrageenan induced rat paw oedema.

\begin{tabular}{lccc} 
Treatment & Dose $(\mathrm{mg} / \mathrm{kg})$ & Increase in paw volume $(\mathrm{mL})$ & Inhibition (\%) \\
Control & - & $0.784 \pm 0.13$ & - \\
MESC & 100 & $0.493 \pm 0.08^{*}$ & 37.11 \\
\hline MESC & 200 & $0.342 \pm 0.04^{*}$ & 56.37 \\
Indomethacin & 10 & $0.219 \pm 0.02^{*}$ & 72.06 \\
\hline
\end{tabular}

Values are mean $\pm \operatorname{SEM}(n=6) .{ }^{*} \mathrm{P}<0.001$, compared to control group.

Table 2. Effect of MESC on histamine induced rat paw oedema.

\begin{tabular}{lccc} 
Theatment & Dose $(\mathrm{mg} / \mathrm{kg})$ & Increase in paw volume $(\mathrm{mL})$ & Inhibition (\%) \\
Control & - & $0.592 \pm 0.024$ & - \\
MESC & 100 & $0.351 \pm 0.008^{*}$ & 40.70 \\
\hline MESC & 200 & $0.290 \pm 0.015^{*}$ & 51.01 \\
Indomethacin & 10 & $0.219 \pm 0.006^{*}$ & 63.00 \\
\hline
\end{tabular}

Values are mean $\pm \operatorname{SEM}(n=6) .{ }^{*} \mathrm{P}<0.001$, compared to control group.

Table 3. Effect of MESC on serotonin induced rat paw oedema.

\begin{tabular}{lccc} 
Treatment & Dose $(\mathrm{mg} / \mathrm{kg})$ & Increase in paw volume $(\mathrm{mL})$ & Inhibition (\%) \\
Control & - & $0.657 \pm 0.007$ & - \\
MESC & 100 & $0.399 \pm 0.011^{*}$ & 39.26 \\
\hline MESC & 200 & $0.271 \pm 0.005^{*}$ & 58.75 \\
Indomethacin & 10 & $0.190 \pm 0.003^{*}$ & 71.08 \\
\hline
\end{tabular}

Values are mean $\pm \operatorname{SEM}(n=6) .{ }^{*} \mathrm{P}<0.001$, compared to control group.

Table 4. Effect of MESC on cotton pouch induced granuloma in rats.

\begin{tabular}{lccc} 
Theatment & Dose $(\mathbf{m g} / \mathrm{kg})$ & $\begin{array}{c}\text { Increased wt of cotton pellet } \\
(\mathbf{m g}) \pm \text { SEM }\end{array}$ & $\begin{array}{c}\text { Inhibition (\%) } \\
\text { Control }\end{array}$ \\
MESC & - & $38.23 \pm 0.18$ & - \\
\hline MESC & 100 & $24.72 \pm 0.35^{*}$ & 35.33 \\
Indomethacin & 10 & $17.05 \pm 0.27^{*}$ & 55.40 \\
\hline
\end{tabular}

Values are mean $\pm \operatorname{SEM}(n=6) . * P<0.001$, compared to control group. 
a biphasic response. The early phase (1-2 h) of the carrageenan model is mainly mediated by histamine and serotonin (5-HT). The late phase $(2-4 \mathrm{~h})$ is mediated by bradykinin, leukotrienes, polymorphonuclear cells and prostaglandins produced by tissue macrophages. 14 The MESC produced dose dependent and significant $(\mathrm{P}<0.001)$ inhibition of carrageenan-induced paw oedema after a period of $4 \mathrm{~h}$.

The MESC also significantly $(\mathrm{P}<0.001)$ suppressed the inflammation produced by the putative inflammatory mediators viz. histamine and serotonin in a dose related manner. It indicates that the MESC inhibited the inflammation caused by carrageenan and mediators. The cotton pellet method is widely used to evaluate the exudative and proliferative components of the chronic inflammation. 15 Chronic inflammation is a reaction arising when the acute response is insufficient to eliminate the pro-inflammatory agents. Chronic inflammation includes a proliferation of fibroblasts and the infiltration of neutrophils and exudation. Chronic inflammation occurs by the development of proliferative cells. These cells can either spread or remain in granuloma form. The dry weight of the cotton pellets correlates with the amount of the granulomatous tissue formed.16 The MESC showed significant $(\mathrm{P}<0.001)$ and dose dependent anti-inflammatory action in cotton pellet induced granuloma and hence found to be effective in chronic inflammatory conditions. Based on the present results it can be concluded that the MESC demonstrated antiinflammatory potential in both acute and chronic phases of inflammation. The gotten dose-dependent effect is relative and it would be necessary to use several doses to confirm it and to get the real dose having the maximum effect.

It is pertinent to mention here that previous workers reported anti-inflammatory and antiallergic activities of $S$. cumini stem bark. ${ }^{17,18}$
The results of the present study confirmed acute and chronic anti-inflammatory effects of its leaves, thereby indicating that likewise bark, the leaves are also effective in counteracting inflammatory conditions.

The present preliminary investigation confirms that $S$. cumini leaf possessed remarkable acute and chronic anti-inflammatory properties in the experimented rodent models. The outcome of present study can substantiate its traditional usage in Indian subcontinent. Further studies are presently underway to confirm the molecular mechanisms and to identity the bioactive principles responsible for these actions.

\section{References}

1. Chopra RN, Nayer SL, Chopra I. Glossary of Indian Medicinal Plants. New Delhi, India: Council of Scientific and Industrial Research; 1956.

2. Indira G, Mohan RM. Jamun Fruits. Hyderabad, India: National Institute of Nutrition, Indian Council of Medical Research; 1992.

3. Nadkarni AK. Indian Materia Medica. Bombay, India: Popular Prakashan; 1954.

4. Warrier PK, Nambiar VPK, Ramankutty C. Indian Medicinal Plants. Hyderabad, India: Orient Longman Ltd.; 1996.

5. Khare CP. Indian Medicinal Plants: An Illustrated Dictionary. Berlin, Heidelberg: Springer; 2007.

6. Harborne JB. Phytochemical methods, A Guide to Modern Techniques of Plant Analysis. New Delhi, India: Springer Pvt. Ltd.; 1998.

7. Dixon WJ. The up-and-down methods for small animals. J Am Stat Assoc 1965;60: 967.

8. Winter CA, Risley EA, Nuss, GW. Carrageenan-induced oedema in hind paw of the rats as assay for antiinflammatroy drugs. Exp Biol Med 1962;111:544-7.

9. Bhattacharya S, Haldar PK, Zaman MK. Anti-inflammatory and in vitro antioxidant property of Zanthoxylum nitidum root. Curr Trends Biotech Pharm 2010;4:774-83.

10. Suleyman H, Demirezer LO, Kuruuzum, A, et al. Antiinflammatory effect of the aqueous extract from Rumex patientia L. roots. J Ethnopharmacol 1991;65:141-8.

11. Parmar, NS, Ghosh MN. Antiinflammatory activity of gossypin a bioflavonoid isolated from Hibiscus vitifolius Linn. Indian $\mathbf{J}$ Pharmacol 1978;10:277-93.

12. D'Arcy PF, Haward EM, Muggleton RW, Townsend SB. The anti-inflammatory action of gresiofulvin in experimental animals. J Pharm Pharmacol 1960;12:659-65.

13. Winter CA, Porter CC. Effect of alteration in the side chain upon anti-inflammatory activity and liver glycogen activities in hydrocortisone esters. J Am Pharmacol Soc 1957;46:515.

14. Brito ARMS, Antonio MA. Oral anti-inflammatory and antiulcerogenic activities of a hydroalcoholic extract and partitioned fractions of Turnera ulmifolia (Turneraceae). J Ethnopharmacol 1998;61: 215-28.

15. Ghosh MN. Fundamentals of Experimental Pharmacology. Kolkata, India: Hilton \& Co.; 2008.

16. Olajide OA, Awe SO, Makinde JM. Effect of the aqueous extract of Bridelia ferruginea stem bark on carrageenan-induced edema and granuloma tissue formation in rat and mice. J Ethnopharmacol 1999;66:113-7.

17. Muruganandan S, Srinivasan K, Chandra $\mathrm{S}$, et al. Anti- inflammatory activity of Syzygium cumini bark. Fitoterapia 2001; 72:369-75.

18. Brito FA, Lima LA, Ramos MF, et al. Pharmacological study of anti-allergic activity of Syzygium cumini (L.) Skeels. Braz J Med Biol Res 2007;40:105-15. 